\title{
Extrapendicular Approach of Unilateral Percutaneous Vesselplasty for the Treatment of Kummell Disease
}

\author{
MINSHENG PIAO, MD, PhD, ${ }^{1}$ ALOYSIUS BAMBANG DARWONO, MD, PhD ${ }^{2}$ KELIN ZHU, MD, ${ }^{1}$ KAI \\ ZHAO, MD ${ }^{1}$ \\ ${ }^{I}$ Department of Orthopedics, Jiaxing Banger Orthopaedic Hospital, Jiaxing, China, ${ }^{2}$ Gading Pluit Hospital, Jakarta, Indonesia
}

\begin{abstract}
Background: Our purpose was to evaluate the efficacy of the extrapendicular approach for unilateral percutaneous vesselplasty in dealing with Kummell disease patients.

Methods: Twenty-seven patients undergoing vesselplasty at our institution were enrolled in the study. Vesselplasty was performed using percutaneous extrapendicular technique. Pain, restoration of vertebral body height, and cement leakage were evaluated in the process.

Results: Substantial pain relief was attained in all the patients. The visual analogue scale improved significantly from pre- to postoperation $(P<.05)$, and remained unchanged at every follow-up. The anterior vertebral body heights were significantly corrected after operation $(P<.05)$. No cement leakage was found.

Conclusion: This new technique of vesselplasty offers statistically significant benefits in Kummell disease patients. It also makes vesselplasty feasible, safe, and effective.

New Technology

Keywords: extrapendicular, Kummell disease, percutaneous, percutaneous vesselplasty
\end{abstract}

\section{INTRODUCTION}

Kummell disease is a rare type of vertebral avascular necrosis first described by Hermann Kummell in $1895 .^{1}$ It is characterized by patients suffering a trivial spinal trauma, but developing a symptomatic, progressive, angular kyphosis after a symptom-free period of months to years. It is a complication of vertebral compression fractures (VCFs). Since the original description, multiple terms have been used to describe this pathology: vertebral osteonecrosis, pseudoarthrosis of vertebral fracture, $\mathrm{VCF}$ nonunion, intravertebral vacuum cleft, and delayed vertebral collapse. ${ }^{2-4}$ With the advent of radiographic technology, it was recognized that this uncommon spinal disorder represented posttraumatic vertebral fractures, which present with unobvious initial X-rays findings, but subsequent vertebral body collapse. ${ }^{5,6}$

Kummell disease occurs primarily in middle-aged and elderly patients, with a slight male predominance, suggesting that the prevalence will increase as the population ages. In the last half century, there have been very few published reports on cases that meet the criteria set by Kummell. ${ }^{6}$ Although the concept of Kummell disease is ambiguous, with the advancement of preoperative radiographic evaluations of vertebral status, in particular with the population of magnetic resonance imaging, more and more VCFs are found to be Kummell disease. ${ }^{7}$

The conventional management of symptomatic VCFs is medical therapy, which includes analgesics, bed rest, external bracing, and rehabilitation. ${ }^{8,9}$ These treatments are only partially effective and do not prevent kyphotic deformity. ${ }^{9}$ Moreover, bed rest accelerates bone resorption and leads to an increased risk of future fractures. Surgery is generally limited to cases of spinal instability or neurologic deficit. ${ }^{10-12}$ However, surgical fixation often fails because of the poor quality of osteoporotic bone. ${ }^{10}$ For these reasons, physicians have become interested in new methods for pain relief and functional restoration with the goal that patients may return to their activities of daily living. ${ }^{13}$

Vertebroplasty and balloon kyphoplasty are two minimally invasive percutaneous approaches developed for the treatment of symptomatic VCFs.

Percutaneous vertebroplasty (PVP) was first performed in $1984 .{ }^{14}$ It is an imaging-guided procedure in which polymethylmethacrylate 
(PMMA) is percutaneously injected into the vertebral body with the fracture. Although not well established, the most likely mechanism for pain relief after vertebroplasty treatment appears to be mechanical stabilization of the vertebral body. In most ex vivo studies, injection of cement into the vertebral body restored its stiffness and increased its strength. ${ }^{15}$ The main risks of this technique are leakage of PMMA into the venous system, with the possibility of pulmonary embolism, or into the spinal canal or neural foramina, precipitating neurologic disorders.

Percutaneous balloon kyphoplasty, a modification of vertebroplasty, involves inflation of a highpressure balloon (KyphX Inflatable Bone Tamps, Kyphon) within the collapsed vertebral body followed by percutaneous injection of bone cement into the cavity created by the balloon. ${ }^{16}$ This procedure was devised and first performed in 1998. ${ }^{17}$ The risk of cement extravasation is reduced with balloon kyphoplasty because of the lowerpressure injection of high-viscosity cement into a previously formed cavity, ${ }^{18}$ with new bone margins created by the compressed trabeculae.

Vesselplasty is a new intriguing alternative to vertebroplasty and kyphoplasty. It was devised to obtain control of the volume of void created in the vertebral body, prevent the leakage of bone filler material, and restore vertebral body height. Designed by Jerry Lin, the chairman of A-Spine Holding Group Corporation (Taipei, Taiwan), vesselplasty was first performed in 2004 by Darwono (Darwono B, presented at the 2004 Triennial Asia Pacific Orthopedic meeting, Kuala Lumpur, Malaysia). Instead of using a balloon to create a cavity, vesselplasty uses a polyethylene terephthalate (PET) balloon container (Vessel-X, A-Spine Holding Group Corporation) to restore the height of the vertebral body. This receptacle serves as both a vertebral body expander and a bone cement container. It is introduced into the vertebra in its reduced configuration and, once positioned within the vertebra, is expanded by the injection of PMMA. Then, owing to the porous structure comprising the fibers of the PET vessel, a small amount of bone cement permeates through its wall and interdigitates within the vertebral body to increase its stability. Theoretically, this technique solves the problem of leakage of cement from the vertebral body, because most of the cement is contained by the expandable artificial vessel, providing a safe method to treat Kummell disease.

In this article, we describe performance of percutaneous vesselplasty via a unilateral extrapedicular approach to improve the syndrome in patients diagnosed with Kummell disease.

\section{MATERIALS AND METHODS}

Twenty-seven patients undergoing percutaneous vesselplasty to treat Kummell disease at Zhejiang Xin'an International Hospital from December 2014 to November 2016 were enrolled in our study. The mean age of the patients was 83 years old (Table 1 ). Each patient had severe back pain. Radiographs demonstrated a burst fracture with a vacuum phenomenon for each patient (Figure 1). Patients with previous spine surgery, infection, tumor, or neurological impairment were excluded.

The efficacy of vesselplasty was evaluated using the visual analog scale for pain (VAS). In addition, radiographic data, including the anterior vertebral height and the leakage of bone cement were measured. Clinical examinations were performed prior to surgery and postoperatively (1 day, 3 days, and 1 month after vesselplasty).

\section{Surgical Technique}

Local anesthesia was administered to the patient prior to the surgery. The patient was placed in the prone position and injection needles were used to pass through the skin and puncture the edge of vertebra with a unilaterally external approach. A puncture needle $3.5 \mathrm{~mm}$ in diameter was advanced unilaterally through skin into the vertebral body. A $\mathrm{C}$-arm machine monitored the needle inserted into the vertebral body center. The needle was exchanged for a working cannula over a $\mathrm{K}$-wire $1.5 \mathrm{~mm}$ in diameter through which a drill trocar was advanced creating a channel for the PET balloon container. Before the balloon container was advanced into the vertebral body, the liquid had to be extracted. The drill trocar was removed and the inflatable balloon container was advanced into the anterior one-third of the vertebral body under $\mathrm{C}$-arm machine monitoring. The balloon was inflated under C-arm machine guidance to no more than 200 psi. PMMA cement was injected into balloon container when it became doughy and could stand at the tip of the bone cement inserter. Injection of PMMA was performed under fluoroscopic guidance and contin- 
Table 1. Characteristics of patients.

\begin{tabular}{lc}
\hline & Numbers \\
\hline Gender & \\
Male & 5 \\
Female & 22 \\
Age & $62-92$ \\
Vertebral Level & \\
T11 & 4 \\
T7 & 1 \\
T8 & 1 \\
T12 & 9 \\
L1 & 11 \\
L2 & 1 \\
\hline
\end{tabular}

ued until maximal expansion of the PET vessel. The volume of bone cement injected into the vertebra was a mean of $2 \mathrm{~mL}$ (Figure 2). The vessel introducer and the pushing rod were removed, followed by the cannula tube. Once these elements had been removed, the posterior opening of the PET balloon container was mostly sealed because of the cement's short solidification time. After the surgery, the patients were required to rest for 6 hours, and during this period the vital signs, neurology, sensory motor functions of the lower limbs were monitored.

We used VAS and anterior vertebral body height to evaluate the effects of our novel technique.

\section{Statistical Analysis}

Continuous data were expressed as the mean \pm SD. A comparison of continuous variables pre- and postsurgery was performed using a oneway analysis of variance. $P \leq .05$ was considered to indicate a statistically significant difference.

\section{RESULTS}

The percutaneous vesselplasty procedures performed on the patients with Kummell disease were successful and without severe complications. The success rate of the puncture surgery was $100 \%$. The clinical assessments of the patients were performed at 24 hours, 3days, and 1month postsurgery.

All the patients in our study showed that the VAS and anterior vertebral height significantly improved at 1 day postoperatively $(P<.05)$, and the improvement was sustained before discharge. Cement leakages were zero in all the patients. The mean preoperative VAS score was $8.7 \pm 0.3$. Substantial pain relief was achieved with each patient. The mean postoperative VAS score reduced to $2.3 \pm 0.5$ at 1 day postprocedure. The effect of pain control was persistent. The average VAS changed slightly at every follow-up (Table 2).

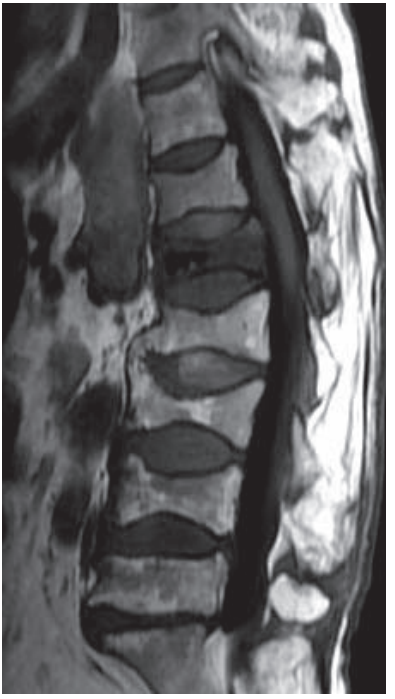

(A)

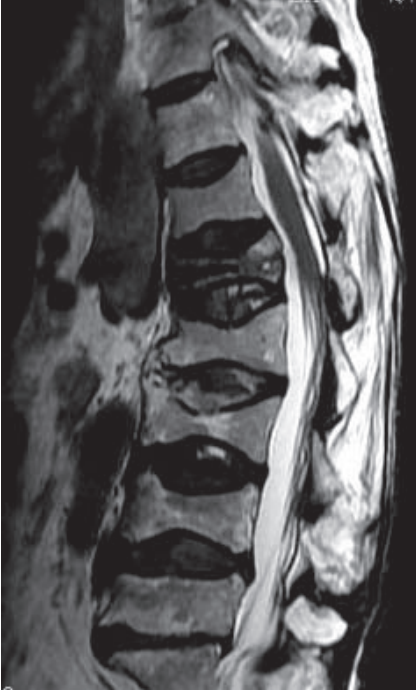

(B)
Figure 1. Sagittal T1-weighted (A) and T2-weighted (B) magnetic resonance images of an 83-year-old woman with Kummell disease at the L1 level.

The mean postoperative anterior vertebral body heights were significantly increased compared with preoperative heights (Figure 3; Table 2). There were no significant differences between the immediate postoperative and follow-up assessments. No cement leakage into the spinal canal and no further dislodging of the posterior vertebral body fragments occurred.

\section{DISCUSSION}

Kummell disease is defined as delayed posttraumatic vertebral collapse and often occurs in patients with osteoporosis, extensive spondylosis, or advanced age, or those undergoing long-term steroid therapy. Involvement of a single vertebral body is most common. The fractured and necrotic vertebral body typically is located in the thoracic or lumbar spine with the T12 vertebral body being the most commonly affected. ${ }^{19}$

Treatment for Kummell disease remains controversial. Although early reports were centered on conservative treatment such as bracing and bed rest, more recent reports favor surgical intervention. Heini reported that $36 \%$ of VCFs are progressive, and conservative treatment is not effective for these aging cases with cord compression. ${ }^{20}$ For the aged patients, long-term lying in bed can induce many complications, some of which are fatal. Surgical intervention is necessary for such conditions. There are some significant clinical challenges and disputes when performing surgical treatment for osteoporot- 

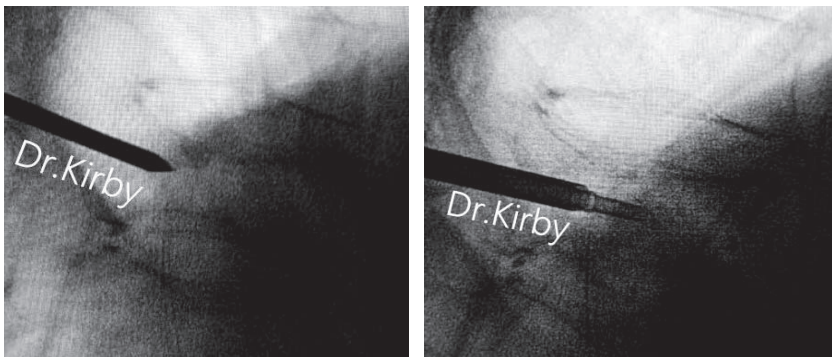

(A)

(B)
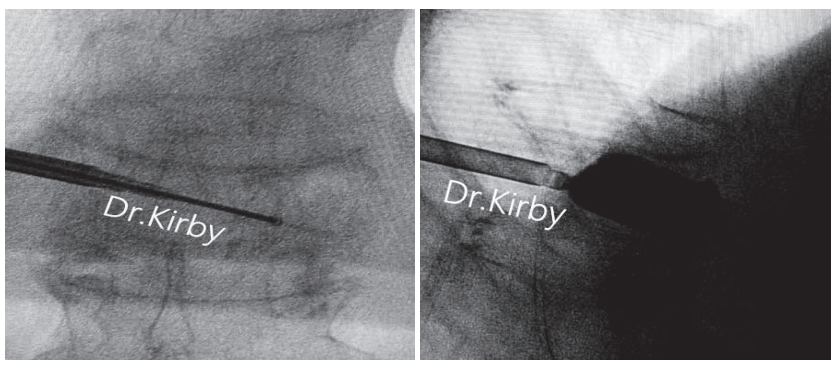

(C)

(D)

Figure 2. Photographs show percutaneous vesselplasty procedure with Carm imaging; the cement is injected with an external approach to the vertebra.

ic vertebral collapse with neurological deficits. ${ }^{21-23}$ The advantages of surgery include earlier patient ambulation and correction of the kyphotic deformity. However, extensive surgical intervention in the early stages remains challenging because of medical comorbidities or fixation complication secondary to osteoporosis. Early disease can be treated effectively by PVP or percutaneous kyphoplasty (PKP), allowing mobilization earlier than that by conventional open techniques. However, PVP has been reported to have a higher risk of cement leakage than PKP. ${ }^{24}$ Our study evaluated the effectiveness of vesselplasty for treating patients with Kummell disease. To our knowledge, this study is the first of its kind about this procedure.

Effects of PKP in treating osteoporotic VCFs have been demonstrated in many studies. ${ }^{25-30}$ Due to disadvantages of longer operation time, more surgical trauma, and higher doses of radiation exposure, traditional bilateral PKP has gradually been replaced by unilateral approach. ${ }^{31}$

Complications of PKP include cement extravasation, fractured transverse processes or ribs, dural tears, infection, hematomas, and subsequent

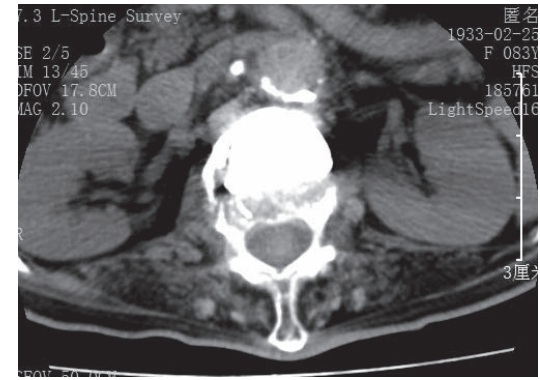

(A)

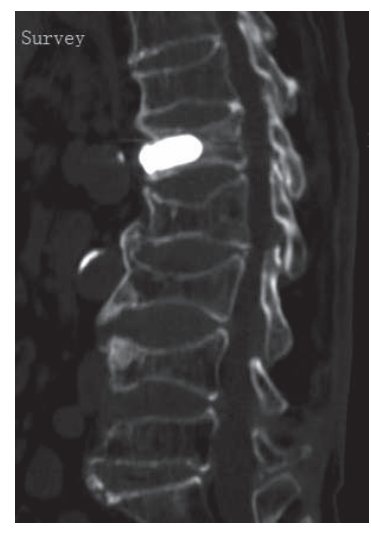

(B)

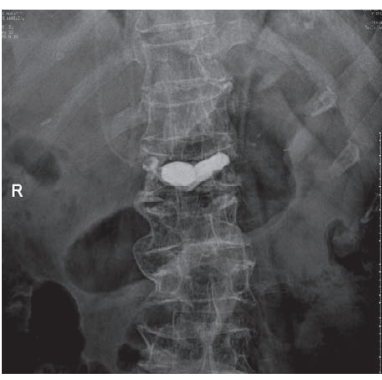

(D)

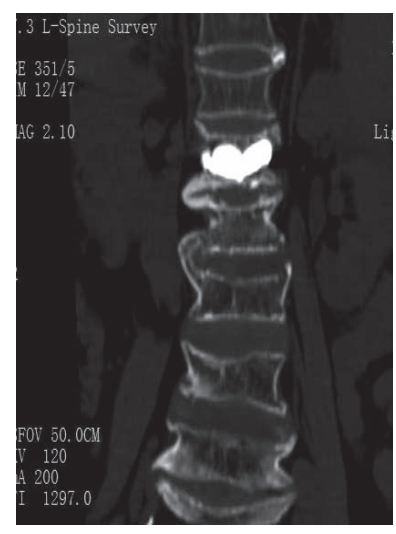

(C)

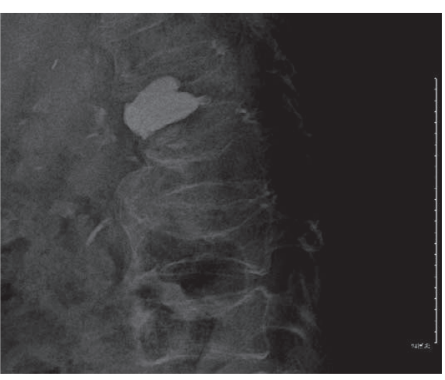

(E)
Figure 3. A 82-year-old woman with Kummell disease at the L1 level on computed tomography and X-ray. Coronal (A), sagittal (B), and axial (C) computed tomography images showed the position of bone cement after operation. Postoperation AP (D) and lateral (E) radiographs of the lumbar spine demonstrate high-density bone cement within the anterior $2 / 3$ of the vertebral body post-percutaneous vesselplasty.

VCF ${ }^{32,33}$ The most common complication is cement extravasation, typically, into epidural, foraminal, intradiscal, and paravertebral veins. Cement leakage into the spinal canal is a devastating complication resulting in spinal cord injury.

Treatment of symptomatic Kummell disease depends on the severity of the patient's pain and the presence of any neurological deficits. Both PVP

Table 2. Mean change in visual analog scale for pain (VAS).

\begin{tabular}{lccc}
\hline & Preoperation & 1 Day Postoperation & 3 Days Postoperation \\
\hline VAS & $8.7 \pm 0.3$ & $2.3 \pm 0.5^{*}$ & $1.8 \pm 0.2^{*}$ \\
\hline
\end{tabular}

$* P<.05$ compared to preoperative value. 
Table 3. Mean improvement of anterior vertebral body height.

\begin{tabular}{lcccc}
\hline & Preoperation & 1 Day Postoperation & 3 Days Postoperation & 1 Month Postoperation \\
\hline Heights $(\mathrm{mm})$ & $17.72 \pm 1.69$ & $27.48 \pm 2.06^{*}$ & $27.27 \pm 1.39^{*}$ & $26.89 \pm 1.63^{*}$ \\
\hline
\end{tabular}

$* P<.05$ compared to preoperative value.

and PKP have been shown to restore vertebral height and alleviate pain markedly. Pain relief is thought to be due to the filling the entire cleft with cement is important to ensure a pain-free postoperative period. ${ }^{34,35}$ Pain was markedly relieved in all the patients in our study at 1 day postoperatively.

In this study, at 1 day postoperatively, we found the restoration of the anterior vertebral height was from 17.72 to $27.48 \mathrm{~mm}$. For Kummell disease, the vertebral height varies with postural changes because of the cleft and thus the anterior vertebral height can be significantly corrected in an extended posture.

In Kummell disease with severe spinal canal stenosis, the posterior vertebral wall is always collapsed, which increases the potential risk of cement leakage into the spinal canal and further spinal canal compromise during PVP or PKP. ${ }^{36,37}$ Concerning the higher rate of cement leakage in PVP than PKP, our study chose the unilateral extrapedicular approach of percutaneous vesselplasty and no obvious cement leakage or neurological deterioration were found.

As patients with Kummell disease may have had an empty space surrounded by fibrotic tissues, the cement leakage may be reduced by those fibrotic tissues. In order to distribute the cement more viscously, Greene et al designed an eggshell technique, which included another balloon placement once the cement had been inserted. ${ }^{38}$

In most of the procedures reported in this work, the percutaneous vesselplasty approach was the best one for Kummell disease treatment. This surgical method is intended to avoid the risk related to leakage of cement. The absence of symptomatic complication in our study population attests to the safety of the vesselplasty procedure. To our knowledge, this new technique used in Kummell disease has not been reported in the literature, so there are no studies with which to compare our results.

Pain, mobility, and vertebral heights improved significantly after vesselplasty in our study $(P<.05)$. Neurological function improvement can be maintained during the follow-up period for the patients. The extrapendicular approach of percutaneous vesselplasty needs only a short operation time, and is accomplished without much bleeding.
So it is suitable for these patients who are not good in general health and cannot endure a spinalshortening procedure. It can relieve pain quickly and stabilize a fractured vertebral body instantly. Besides, it's worth mentioning that our novel technique requires a lower cost and lower doses of radiation exposure compared with other techniques. Nonetheless, its long-term outcome still needs further clinical observation.

The present research still has some limitations for a small number of patients, which possibly affected the statistical power. Another, the study had a only a short follow-up period. Therefore, additional prospective studies may aid in gathering more definitive evidence.

In summary, the results of our novel technique prove that it offers statistically significant benefits in the improvement of pain, mobility, and the anterior vertebral body heights in patients with Kummell disease. The extrapendicular approach of percutaneous vesselplasty is an effective, minimally invasive procedure for the treatment of Kummell disease that can achieve equal biomechanical strength with less bone cement and lower doses of radiation exposure.

\section{REFERENCES}

1. Kummell H. Die rarefizierende Ostitis der Wirbelkorper. Deutsche Med. 1895;21:180-181.

2. Chou LH, Knight RQ. Idiopathic avascular necrosis of a vertebral body. Case report and literature review. Spine (Phila Pa 1976). 1997;22(16):1928-1932.

3. Freedman BA, Heller JG. Kummel disease: a not-so-rare complication of osteoporotic vertebral compression fractures. $J$ Am Board Fam Med. 2009;22(1):75-78.

4. Jang JS, Kim DY, Lee SH. Efficacy of percutaneous vertebroplasty in the treatment of intravertebral pseudarthrosis associated with noninfected avascular necrosis of the vertebral body. Spine (Phila Pa 1976). 2003;28(14):1588-1592.

5. Matzaroglou C, Georgiou CS, Assimakopoulos K, Saridis A, Khudiaev AT, Giannakenas C. Kummell's disease: a rare spine entity in a young adult. Hell J Nucl Med. 2010;13(1):5255 .

6. Swartz K, Fee D. Kummell's disease: a case report and literature review. Spine (Phila Pa 1976). 2008;33(5):E152-E155.

7. Chen B, Fan S, Zhao F. Percutaneous balloon kyphoplasty of osteoporotic vertebral compression fractures with intravertebral cleft. Indian J Orthop. 2014;48(1):53-59.

8. Rapado A. General management of vertebral fractures. Bone. 1996;18(3 Suppl):191S-196S. 
9. Reginster $\mathbf{J}$, et al. Randomized trial of the effects of risedronate on vertebral fractures in women with established postmenopausal osteoporosis. Vertebral Efficacy with Risedronate Therapy (VERT) Study Group. Osteoporos Int. 2000;11(1):83-91.

10. Dickman CA, Minne HW, Sorensen OH, et al. Transpedicular screw-rod fixation of the lumbar spine: operative technique and outcome in 104 cases. J Neurosurg. 1992;77(6):860-870.

11. Esses SI, Sachs BL, Dreyzin V. Complications associated with the technique of pedicle screw fixation. A selected survey of ABS members. Spine (Phila Pa 1976). 1993;18(15):2231-2238; discussion 2238-2239.

12. Taylor RS, Taylor RJ, Fritzell P. Balloon kyphoplasty and vertebroplasty for vertebral compression fractures: a comparative systematic review of efficacy and safety. Spine (Phila Pa 1976). 2006;31(23):2747-2755.

13. Lavelle W, et al. Vertebroplasty and kyphoplasty. Med Clin North Am. 2007;91(2):299-314.

14. Galibert P, Deramond H, Rosat P, Le Gars D. Preliminary note on the treatment of vertebral angioma by percutaneous acrylic vertebroplasty [in French]. Neurochirurgie. 1987;33(2):166-168.

15. Mathis JM, Barr JD, Belkoff SM, Barr MS, Jensen ME, Deramond H. Percutaneous vertebroplasty: a developing standard of care for vertebral compression fractures. AJNR Am J Neuroradiol. 2001;22(2):373-381.

16. Coumans JV, Reinhardt MK, Lieberman IH. Kyphoplasty for vertebral compression fractures: 1-year clinical outcomes from a prospective study. J Neurosurg. 2003;99(1 Suppl):44-50.

17. Garfin SR, Yuan HA, Reiley MA. New technologies in spine: kyphoplasty and vertebroplasty for the treatment of painful osteoporotic compression fractures. Spine (Phila $\mathrm{Pa}$ 1976). 2001;26(14):1511-1515.

18. Lieberman I, Reinhardt MK. Vertebroplasty and kyphoplasty for osteolytic vertebral collapse. Clin Orthop Relat Res. 2003(415 Suppl):S176-S186.

19. Osterhouse MD, Kettner NW. Delayed posttraumatic vertebral collapse with intravertebral vacuum cleft. J Manipulative Physiol Ther. 2002;25(4):270-275.

20. Heini PF. The current treatment - a survey of osteoporotic fracture treatment. Osteoporotic spine fractures: the spine surgeon's perspective. Osteoporos Int. 2005;16(Suppl 2):S85-S92.

21. Karlsson MK, Hasserius R, Gerdhem P, Obrant KJ, Ohlin A. Treatment of osteoporotic vertebral compression. Explosive interest for vertebroplasty and kyphoplasty [in Swedish]. Lakartidningen. 2005;102(21):1644-1648.

22. Liu JT, Liao WJ, Tan WC, et al. Balloon kyphoplasty versus vertebroplasty for treatment of osteoporotic vertebral compression fracture: a prospective, comparative, and randomized clinical study. Osteoporos Int. 2010;21(2):359-364.

23. Alexandru D, So W. Evaluation and management of vertebral compression fractures. Perm J. 2012;16(4):46-51.

24. Han S, Wan S, Ning L, Ting L, Tong Y, Zhang J, Fan S. Percutaneous vertebroplasty versus balloon kyphoplasty for treatment of osteoporotic vertebral compression fracture: a meta-analysis of randomised and non-randomised controlled trials. Int Orthop. 2011;35(9):1349-1358.

25. Bae $\mathrm{H}$, Shen $M$, Maurer $P$, et al. Clinical experience using Cortoss for treating vertebral compression fractures with vertebroplasty and kyphoplasty: twenty four-month follow-up. Spine (Phila Pa 1976). 2010;35(20):E1030-1036.

26. Wardlaw D, Cummings SR, Van Meirhaeghe J, et al. Efficacy and safety of balloon kyphoplasty compared with nonsurgical care for vertebral compression fracture (FREE): a randomised controlled trial. Lancet. 2009;373(9668):1016-1024.

27. Zoarski GH, Snow P, Olan WJ, et al. Percutaneous vertebroplasty for osteoporotic compression fractures: quantitative prospective evaluation of long-term outcomes. $J$ Vasc Interv Radiol. 2002;13(2 Pt 1):139-148.

28. Heran MK, Legiehn GM, Munk PL. Current concepts and techniques in percutaneous vertebroplasty. Orthop Clin North Am. 2006;37(3):409-434, vii.

29. Barr JD, Barr MS, Lemley TJ, McCann RM. Percutaneous vertebroplasty for pain relief and spinal stabilization. Spine (Phila Pa 1976). 2000;25(8):923-928.

30. Bouza C, López T, Magro A, Navalpotro L, Amate JM. Efficacy and safety of balloon kyphoplasty in the treatment of vertebral compression fractures: a systematic review. Eur Spine J. 2006;15(7):1050-1067.

31. Mroz TE, Yamashita T, Davros WJ, Lieberman IH. Radiation exposure to the surgeon and the patient during kyphoplasty. J Spinal Disord Tech. 2008;21(2):96-100.

32. Lee MJ, Dumonski M, Cahill P, Stanley T, Park D, Singh K. Percutaneous treatment of vertebral compression fractures: a meta-analysis of complications. Spine (Phila $\mathrm{Pa}$ 1976). 2009;34(11):1228-1232.

33. Abdelrahman H, Siam AE, Shawky A, Ezzati A, Boehm H. Infection after vertebroplasty or kyphoplasty. A series of nine cases and review of literature. Spine J. 2013;13(12):18091817.

34. Lane JI, Maus TP, Wald JT, Thielen KR, Bobra S, Luetmer PH. Intravertebral clefts opacified during vertebroplasty: pathogenesis, technical implications, and prognostic significance. AJNR Am J Neuroradiol. 2002;23(10):1642-1646.

35. McKiernan F, Faciszewski T. Intravertebral clefts in osteoporotic vertebral compression fractures. Arthritis Rheum. 2003;48(5):1414-1419.

36. Krauss M, Mirschfelder H, Tomandi B, Lichti G, Bär I. Kyphosis reduction and the rate of cement leaks after vertebroplasty of intravertebral clefts. Eur Radiol. 2006;16(5):1015-1021.

37. Yang H, Gan M, Zou J, et al. Kyphoplasty for the treatment of Kummell's disease. Orthopedics. 2010;33(7):479.

38. Greene DL, Isaac R, Neuwirth M, Bitan FD. The eggshell technique for prevention of cement leakage during kyphoplasty. J Spinal Disord Tech. 2007;20(3):229-232.

Corresponding Author: Kai Zhao, MD, Department of Orthopedics, Jiaxing Banger Orthopaedic Hospital, Jiaxing, China. Phone: 0 (000) 0000000; Email: Kirbyzh@vip.sina.com.

Published 30 April 2019

This manuscript is generously published free of charge by ISASS, the International Society for the Advancement of Spine Surgery. Copyright (C) 2019 ISASS. To see more or order reprints or permissions, see http://ijssurgery.com. 